\title{
Best Proximity Point for Generalized Proximal Weak Contractions in Complete Metric Space
}

\author{
Erdal Karapınar, ${ }^{1}$ V. Pragadeeswarar, ${ }^{2}$ and M. Marudai ${ }^{2}$ \\ ${ }^{1}$ Department of Mathematics, Atilim University, Incek, 06836 Ankara, Turkey \\ ${ }^{2}$ Department of Mathematics, Bharathidasan University, Tiruchirappalli, Tamil Nadu 620 024, India \\ Correspondence should be addressed to Erdal Karapınar; erdalkarapinar@yahoo.com
}

Received 19 September 2013; Accepted 29 October 2013; Published 16 January 2014

Academic Editor: Francis T. K. Au

Copyright (c) 2014 Erdal Karapinar et al. This is an open access article distributed under the Creative Commons Attribution License, which permits unrestricted use, distribution, and reproduction in any medium, provided the original work is properly cited.

\begin{abstract}
We introduce a new class of nonself-mappings, generalized proximal weak contraction mappings, and prove the existence and uniqueness of best proximity point for such mappings in the context of complete metric spaces. Moreover, we state an algorithm to determine such an optimal approximate solution designed as a best proximity point. We establish also an example to illustrate our main results. Our result provides an extension of the related results in the literature.
\end{abstract}

\section{Introduction and Preliminaries}

A self-mapping $T$, defined on a metric space $(X, d)$, is said to be a contraction if there exists a constant $k \in[0,1)$ such that the inequality $d(T x, T y) \leq k d(x, y)$ holds for all $x, y \in X$. Moreover, a self-mapping $T$ is called a contractive mapping if $d(T x, T y)<d(x, y)$ holds for all $x, y \in X$ with $x \neq y$.

The celebrated Banach contraction principle says that if $X$ is complete, then every contraction has a unique fixed point. In fact, the fixed point of a contraction mapping $T$ is obtained as a limit of repeated iteration of the mapping for any (initial) point of $X$. Let $\Phi$ be the class of continuous, nondecreasing mapping $\phi:[0, \infty) \rightarrow[0, \infty)$ such that $\phi$ is positive on $(0, \infty)$ and $\phi(0)=0$. A function $\phi \in \Phi$ is called an altering distance function.

A mapping $T: X \rightarrow X$ is called a weak- $\phi$ contraction if there exists a $\phi \in \Phi$ such that $d(T x, T y) \leq d(x, y)-\phi(d(x, y))$ for each $x, y \in X$. The notion of weak- $\phi$ contraction was defined by Alber and Guerre-Delabriere [1] to generalize the well-known Banach contraction principle in the setting of Hilbert spaces. Later, Rhoades [2] noticed that most of the results of Alber and Guerre-Delabriere [1] are valid for any Banach space. Rhoades also proved the following generalization of the Banach contraction principle (see also [3-7]).
Theorem 1. Let $(X, d)$ be a nonempty complete metric space and let $T: X \rightarrow X$ be a weak- $\phi$ contraction on $X$; then $T$ has a unique fixed point.

Recently, Dutta and Choudhury [8] proved the following generalization of Theorem 1 by using $(\psi, \phi)$-weak contraction map.

Theorem 2. Let $(X, d)$ be a nonempty complete metric space and let $T: X \rightarrow X$ be a self-mapping satisfying the inequality

$$
\psi(d(T x, T y)) \leq \psi(d(x, y))-\phi(d(x, y)),
$$

for all $x, y \in X$, where of all function. Then $T$ has a unique fixed point.

Let $\Gamma$ be the class of all function; $\varphi:[0, \infty) \rightarrow[0, \infty)$ is a lower semicontinuous with $\varphi(t)=0$ if and only if $t=0$. In [9] Doric proved the following generalization of Theorem 2 by using generalized $(\psi, \phi)$-weak contractions which contains the $(\psi, \phi)$-weak contractions as a subclass.

Theorem 3. Let $(X, d)$ be a nonempty complete metric space and let $T: X \rightarrow X$ be a generalized $(\psi, \phi)$-weak contraction map; that is, $T$ satisfies the following inequality:

$$
\psi(d(T x, T y)) \leq \psi(m(x, y))-\varphi(m(x, y)),
$$


where $\psi \in \Phi, \varphi \in \Gamma$, and $m(x, y)=\max \{d(x, y), d(T x, x)$, $d(T y, y),(1 / 2)[d(y, T x)+d(x, T y)]\}$ for all $x, y \in X$. Then $T$ has a unique fixed point.

One of the aims of this paper is to extend Theorem 3 via best proximity point. For this purpose, we recollect the basic definitions and fundamentals results as follows.

1.1. Best Proximity Point Theorems. We first recall the notion of best proximity point for nonself-mappings.

Definition 4. Let $(A, B)$ be a pair of two nonempty subsets of a metric space $X$. An element $x \in A$ is said to be a best proximity point of the nonself-mappings $T: A \rightarrow B$ if it satisfies the condition that $d(x, T x)=d(A, B)$ where $A$ and $B$ are nonempty subsets of a metric space.

Best proximity point theorems have been studied to find necessary condition such that the minimization problem $\min _{x \in A} d(x, T x)$ has at least one solution.

Existence and convergence of best proximity point is an interesting topic of optimization theory which recently attracted the attention of many authors [10-15]. A best proximity point theorem for nonself-proximal contractions has been investigated in [16-18].

In this paper, let us consider the mappings $T: A \rightarrow B$, where $A$ and $B$ are nonempty subsets of a metric space $X$ with generalized proximal weak contraction on $T$ which ensure the existence of a unique point $x \in A$ which satisfies $d(x, T x)=$ $d(A, B)$. When the map $T$ is considered to be self-map, then our result reduces to Theorem 3 .

Given nonempty subsets $A$ and $B$ of a metric space $X$, the following notions are used subsequently:

$$
\begin{gathered}
d(A, B):=\inf \{d(x, y): x \in A, y \in B\}, \\
A_{0}=\{x \in A: d(x, y)=d(A, B) \text { for some } y \in B\}, \\
B_{0}=\{y \in B: d(x, y)=d(A, B) \text { for some } x \in A\} .
\end{gathered}
$$

In [13], the authors discussed sufficient conditions which guarantee the nonemptiness of $A_{0}$ and $B_{0}$. Also, in [14], the authors proved that $A_{0}$ is contained in the boundary of $A$.

Definition 5. The set $B$ is said to be approximatively compact with respect to $A$ if every sequence $\left\{y_{n}\right\}$ in $B$ satisfying the condition that $d\left(x, y_{n}\right) \rightarrow d(x, B)$ for some $x$ in $A$ has a convergent subsequence.

Note that every set is approximatively compact with respect to itself and that every compact set is approximatively compact. Further, $A_{0}$ and $B_{0}$ are nonempty if $A$ is compact and $B$ is approximatively compact with respect to $A$.

Let us define the notion of generalized proximal weak contraction maps as follows. For this goal, we first introduce the following class of the mapping. Let $\Omega$ be the set of all function; $\phi:[0, \infty) \rightarrow[0, \infty)$ is nondecreasing with the following property: $\phi(t)=0$ if and only if $t=0$.

Definition 6. A mapping $T: A \rightarrow B$ is said to be a generalized proximal weak contraction on $A$ if there exists functions $\psi, \phi:[0, \infty) \rightarrow[0, \infty)$ satisfying the following condition:

$$
\begin{aligned}
& \left.\begin{array}{l}
d(u, T x)=d(A, B) \\
d(v, T y)=d(A, B)
\end{array}\right\} \Longrightarrow \psi(d(u, v)) \\
& \leq \psi(m(x, y))-\phi(m(x, y)),
\end{aligned}
$$

where $m(x, y)=\max \{d(x, y), d(x, u), d(y, v),(d(x, v)+$ $d(y, u)) / 2\}$ for all $u, v, x, y$ in $A$, where $\psi \in \Phi$ and $\phi \in \Omega$.

Remark 7. Definition 6 guarantees that if a mapping $T$ has a best proximity point then it should be unique. Indeed, we can prove our claim easily. Let $x \in A$ be a best proximity point of $T$. Suppose, on the contrary, that there is another element $y$ such that $d(y, T y)=d(A, B)$. Since $T$ is a generalized proximal weak contraction on $A$, we have

$$
\psi(d(x, y)) \leq \psi(m(x, y))-\phi(m(x, y)),
$$

where $m(x, y)=\max \{d(x, y), d(x, x), d(y, y),(d(x, y)+$ $d(y, x)) / 2\}=d(x, y)$.

From (5), we obtain $\psi(d(x, y)) \leq \psi(d(x, y))-\phi(d(x, y))$, which implies $\phi(d(x, y))=0$, and by our assumption about $\phi$, we get $d(x, y)=0$, or equivalently, $x=y$.

Definition 8. A mapping $T: A \rightarrow B$ is said to be a generalized proximal weak contraction on $B$ if there exist functions $\psi, \phi:[0, \infty) \rightarrow[0, \infty)$ satisfying the following condition:

$$
\begin{aligned}
& \left.\begin{array}{l}
d(u, T x)=d(A, B) \\
d(v, T y)=d(A, B)
\end{array}\right\} \Longrightarrow \psi(d(T u, T v)) \\
& \leq \psi(m(T x, T y))-\phi(m(T x, T y))
\end{aligned}
$$

where $m(T x, T y)=\max \{d(T x, T y), d(T x, T u), d(T y, T v)$, $(d(T x, T v)+d(T y, T u)) / 2\}$ for all $u, v, x, y$ in $A$, where $\psi \in \Phi$ and $\phi \in \Omega$.

For self-mappings, it is clear that every generalized proximal weak contraction on $A$ is a generalized proximal weak contraction on $B$. An operator $T$ is said to be a generalized proximal weak contraction if it is both generalized proximal weak contraction on $A$ and generalized proximal weak contraction on $B$.

\section{Main Results}

We start this section with our main result.

Theorem 9. Let $(A, B)$ be a pair of two nonempty closed subsets of a complete metric space $X$ such that $A_{0}$ is nonempty. Let $T: A \rightarrow B$ be a map satisfying the following conditions:
(i) $T$ is a generalized proximal weak contraction,
(ii) $T\left(A_{0}\right) \subseteq B_{0}$.

Then, there exists a unique $x \in A$ such that $d(x, T x)=d(A, B)$. Further, for any fixed element $x_{0} \in A_{0}$, the sequence $\left\{x_{n}\right\}$, defined by $d\left(x_{n+1}, T x_{n}\right)=d(A, B)$, converges to the element $x$. 
Proof. We prove the theorem in several steps.

Step 1. Let $x_{0} \in A_{0}$. Since $T x_{0} \in T\left(A_{0}\right) \subseteq B_{0}$, there exists $x_{1} \in$ $A_{0}$ such that $d\left(x_{1}, T x_{0}\right)=d(A, B)$. Due to the fact that $T x_{1} \in$ $T\left(A_{0}\right) \subseteq B_{0}$, there exists $x_{2} \in A_{0}$ such that $d\left(x_{2}, T x_{1}\right)=$ $d(A, B)$. Recursively, we find a sequence $\left\{x_{n}\right\}$ in $A_{0}$ such that

$$
d\left(x_{n+1}, T x_{n}\right)=d(A, B), \quad \forall n \in N .
$$

If there exists $n_{0}$ such that $x_{n_{0}}=x_{n_{0}+1}$, then $d\left(x_{n_{0}+1}, T x_{n_{0}}\right)=$ $d\left(x_{n_{0}}, T x_{n_{0}}\right)=d(A, B)$; that is, $x_{n_{0}}$ is a best proximity point of $T$. Thus, the proof is finished. Hence, we suppose that $x_{n} \neq x_{n+1}$ for all $n$. Since $T$ is a generalized proximal weak contraction on $A$, it follows that

$$
\begin{aligned}
\psi\left(d\left(x_{n}, x_{n+1}\right)\right) & \leq \psi\left(m\left(x_{n-1}, x_{n}\right)\right)-\phi\left(m\left(x_{n-1}, x_{n}\right)\right) \\
& \leq \psi\left(m\left(x_{n-1}, x_{n}\right)\right) .
\end{aligned}
$$

Using the monotone property of the $\psi$-function, we get $d\left(x_{n}, x_{n+1}\right) \leq m\left(x_{n-1}, x_{n}\right)$.

Now from the triangle inequality for $d$, we have

$$
\begin{aligned}
& m\left(x_{n-1}, x_{n}\right)=\max \left\{d\left(x_{n-1}, x_{n}\right), d\left(x_{n-1}, x_{n}\right), d\left(x_{n}, x_{n+1}\right),\right.\left.\frac{d\left(x_{n-1}, x_{n+1}\right)+d\left(x_{n}, x_{n}\right)}{2}\right\} \\
&= \max \left\{d\left(x_{n-1}, x_{n}\right), d\left(x_{n}, x_{n+1}\right),\right. \\
&\left.\frac{d\left(x_{n-1}, x_{n+1}\right)}{2}\right\} \\
& \leq \max \left\{d\left(x_{n-1}, x_{n}\right), d\left(x_{n}, x_{n+1}\right),\right. \\
&\left.\frac{d\left(x_{n-1}, x_{n}\right)+d\left(x_{n}, x_{n+1}\right)}{2}\right\} \\
&=\max \left\{d\left(x_{n-1}, x_{n}\right), d\left(x_{n}, x_{n+1}\right)\right\} .
\end{aligned}
$$

If $d\left(x_{n}, x_{n+1}\right) \geq d\left(x_{n-1}, x_{n}\right)$, then $m\left(x_{n-1}, x_{n}\right)=d\left(x_{n}, x_{n+1}\right)>$ 0 . From (8), we obtain $\psi\left(d\left(x_{n}, x_{n+1}\right)\right) \leq \psi\left(d\left(x_{n}, x_{n+1}\right)\right)-$ $\phi\left(d\left(x_{n}, x_{n+1}\right)\right)$, which is a contradiction. So, we have

$$
d\left(x_{n}, x_{n+1}\right) \leq m\left(x_{n-1}, x_{n}\right) \leq d\left(x_{n-1}, x_{n}\right) .
$$

Hence, the sequence $\left\{d\left(x_{n}, x_{n+1}\right)\right\}$ is monotone nonincreasing and bounded. Thus, there exists $r \geq 0$ such that

$$
\lim _{n \rightarrow \infty} d\left(x_{n}, x_{n+1}\right)=\lim _{n \rightarrow \infty} m\left(x_{n-1}, x_{n}\right)=r \geq 0 .
$$

Suppose that $\lim _{n \rightarrow \infty} d\left(x_{n}, x_{n+1}\right)=\lim _{n \rightarrow \infty} m\left(x_{n-1}, x_{n}\right)=$ $r>0$. Then the inequality

$$
\begin{aligned}
\psi\left(d\left(x_{n}, x_{n+1}\right)\right) & \leq \psi\left(m\left(x_{n-1}, x_{n}\right)\right)-\phi\left(m\left(x_{n-1}, x_{n}\right)\right) \\
& \leq \psi\left(m\left(x_{n-1}, x_{n}\right)\right)
\end{aligned}
$$

implies that

$$
\lim _{n \rightarrow \infty} \phi\left(m\left(x_{n-1}, x_{n}\right)\right)=0 .
$$

But as $0<r \leq d\left(x_{n}, x_{n+1}\right) \leq m\left(x_{n-1}, x_{n}\right)$ and $\phi$ is nondecreasing function,

$$
0<\phi(r) \leq \phi\left(m\left(x_{n-1}, x_{n}\right)\right)
$$

and this gives us $\lim _{n \rightarrow \infty} \phi\left(m\left(x_{n-1}, x_{n}\right)\right) \geq \phi(r)>0$ which contradicts to (13). Hence,

$$
\lim _{n \rightarrow \infty} m\left(x_{n-1}, x_{n}\right)=0=\lim _{n \rightarrow \infty} d\left(x_{n}, x_{n+1}\right) .
$$

Step 2. We will show that $\left\{x_{n}\right\}$ is a Cauchy sequence. Suppose, on the contrary, that $\left\{x_{n}\right\}$ is not a Cauchy sequence. Thus, there exists $\epsilon>0$ for which we can find subsequences $\left\{x_{m(k)}\right\}$ and $\left\{x_{n(k)}\right\}$ of $\left\{x_{n}\right\}$ such that $n(k)$ is the smallest index for which $n(k)>m(k)>k, d\left(x_{m(k)}, x_{n(k)}\right) \geq \epsilon$.

This means that

$$
\begin{aligned}
& d\left(x_{m(k)}, x_{n(k)-1}\right)<\epsilon, \\
\epsilon \leq & d\left(x_{m(k)}, x_{n(k)}\right) \\
\leq & d\left(x_{m(k)}, x_{n(k)-1}\right)+d\left(x_{n(k)-1}, x_{n(k)}\right) \\
< & \epsilon+d\left(x_{n(k)-1}, x_{n(k)}\right) .
\end{aligned}
$$

Letting $k \rightarrow \infty$ and by using (15), we conclude that

$$
\lim _{k \rightarrow \infty} d\left(x_{m(k)}, x_{n(k)}\right)=\epsilon .
$$

Again,

$$
\begin{aligned}
& d\left(x_{m(k)}, x_{n(k)-1}\right) \leq d\left(x_{m(k)}, x_{n(k)}\right)+d\left(x_{n(k)}, x_{n(k)-1}\right), \\
& d\left(x_{m(k)}, x_{n(k)}\right) \leq d\left(x_{m(k)}, x_{n(k)-1}\right)+d\left(x_{n(k)}, x_{n(k)-1}\right) .
\end{aligned}
$$

Therefore,

$$
\left|d\left(x_{m(k)}, x_{n(k)-1}\right)-d\left(x_{m(k)}, x_{n(k)}\right)\right| \leq d\left(x_{n(k)}, x_{n(k)-1}\right) .
$$

Letting $k \rightarrow \infty$ and by using (17) together with (15), it follows that

$$
\lim _{k \rightarrow \infty} d\left(x_{m(k)}, x_{n(k)-1}\right)=\epsilon .
$$

Similarly, we derive that

$$
\begin{aligned}
\lim _{k \rightarrow \infty} d\left(x_{m(k)-1}, x_{n(k)}\right) & =\lim _{k \rightarrow \infty} d\left(x_{m(k)-1}, x_{n(k)-1}\right) \\
& =\lim _{k \rightarrow \infty} d\left(x_{m(k)+1}, x_{n(k)}\right) \\
& =\lim _{k \rightarrow \infty} d\left(x_{m(k)}, x_{n(k)+1}\right)=\epsilon .
\end{aligned}
$$

Then, we have

$$
\lim _{k \rightarrow \infty} m\left(x_{m(k)-1}, x_{n(k)-1}\right)=\epsilon .
$$


Using the fact that $T$ is generalized proximal weak contraction on $A$ for $d\left(x_{m(k)}, T x_{m(k)-1}\right)=d(A, B)$ and $d\left(x_{n(k)}, T x_{n(k)-1}\right)=d(A, B)$, we obtain

$$
\begin{aligned}
0<\psi(\epsilon) \leq & \psi\left(d\left(x_{m(k)}, x_{n(k)}\right)\right) \\
\leq & \psi\left(m\left(x_{m(k)-1}, x_{n(k)-1}\right)\right) \\
& -\phi\left(m\left(x_{m(k)-1}, x_{n(k)-1}\right)\right) \\
\leq & \psi\left(m\left(x_{m(k)-1}, x_{n(k)-1}\right)\right) .
\end{aligned}
$$

By using (22) and the continuity of $\psi$ in the above inequality, we find that

$$
\lim _{k \rightarrow \infty} \phi\left(m\left(x_{m(k)-1}, x_{n(k)-1}\right)\right)=0 .
$$

But from $\lim _{k \rightarrow \infty} m\left(x_{m(k)-1}, x_{n(k)-1}\right)=\epsilon$, we can find $k_{0} \in \mathbb{N}$ such that for any $k \geq k_{0}$

$$
\frac{\epsilon}{2} \leq m\left(x_{m(k)-1}, x_{n(k)-1}\right),
$$

and consequently,

$$
0<\phi\left(\frac{\epsilon}{2}\right) \leq \phi\left(m\left(x_{m(k)-1}, x_{n(k)-1}\right)\right) \quad \text { for } k \geq k_{0} .
$$

Therefore, $0<\phi(\epsilon / 2) \leq \phi\left(m\left(x_{m(k)-1}, x_{n(k)-1}\right)\right)$ and this contradicts to (24). Thus, $\left\{x_{n}\right\}$ is a Cauchy sequence in $A$ and hence converges to some element $x$ in $A$. Analogously, by using the fact that $T$ is generalized proximal weak contraction on $B$, we conclude that $\left\{T x_{n}\right\}$ is a Cauchy sequence in $B$. Hence, $\left\{T x_{n}\right\}$ converges to some element $y$ in $B$.

Step 3. Let us now prove that $x$ is best proximity point for $T$.

Recall that $x_{n} \rightarrow x$ in $A$ and $T x_{n} \rightarrow y$ in $B$. Therefore, from (7), we get $d(x, y)=d(A, B)$ and hence $x$ is a member of $A_{0}$. Since $T\left(A_{0}\right) \subseteq B_{0}$, we get $T x \in B_{0}$; hence there exists $z \in A$ such that

$$
d(z, T x)=d(A, B) .
$$

Since $T$ is a generalized proximal weak contraction on $A$, we obtain

$$
\begin{aligned}
\psi\left(d\left(x_{n+1}, z\right)\right) & \leq \psi\left(m\left(x_{n}, x\right)\right)-\phi\left(m\left(x_{n}, x\right)\right) \\
& \leq \psi\left(m\left(x_{n}, x\right)\right)
\end{aligned}
$$

where $m\left(x_{n}, x\right)=\max \left\{d\left(x_{n}, x\right), d\left(x_{n}, x_{n+1}\right), d(x, z),\left(d\left(x_{n}\right.\right.\right.$, $\left.\left.z)+d\left(x, x_{n+1}\right)\right) / 2\right\}$.

By using the fact that $x_{n} \rightarrow x$, we get

$$
\lim _{n \rightarrow \infty} m\left(x_{n}, x\right)=d(x, z) .
$$

Regarding (29) and continuity of $\psi$ in (28), we can obtain

$$
\lim _{n \rightarrow \infty} \phi\left(m\left(x_{n}, x\right)\right)=0 \text {. }
$$

But from $\lim _{n \rightarrow \infty} m\left(x_{n}, x\right)=d(x, z)$ we find $n_{0} \in \mathbb{N}$ such that for any $n \geq n_{0}$

$$
\frac{d(x, z)}{2} \leq m\left(x_{n}, x\right)
$$

and consequently, since $\phi$ is nondecreasing, we get

$$
\phi\left(\frac{d(x, z)}{2}\right) \leq \phi\left(m\left(x_{n}, x\right)\right) \quad \forall n \geq n_{0} .
$$

By using (30) in the inequality above, we get $\phi(d(x, z) / 2)=0$ and from the property of $\phi$, we obtain $d(x, z) / 2=0$ or equivalently, $x=z$. Hence, from (27), we have $d(x, T x)=$ $d(A, B)$.

Example 10. Consider the complete space $X=\mathbb{R}^{2}$ with usual metric.

Suppose that $A:=\{(x, 0): x \in[-2,-1]\}$ and $B:=\{(1, x)$ : $x \in[3 / 2,2]\}$. Then $A$ and $B$ are nonempty closed subsets of $X$ and $A_{0}=\{(-1,0)\}$ and $B_{0}=\{(1,3 / 2)\}$. Note that $d(A, B)=$ $5 / 2$. Let $T: A \rightarrow B$ be defined as

$$
T(x, 0)=\left(1,1-\frac{x}{2}\right), \quad \forall(x, 0) \in A .
$$

Suppose that $\left(u_{1}, 0\right),\left(u_{2}, 0\right),\left(x_{1}, 0\right),\left(x_{2}, 0\right)$ are elements in $A$ such that

$$
d\left(\left(u_{1}, 0\right), T\left(x_{1}, 0\right)\right)=d\left(\left(u_{2}, 0\right), T\left(x_{2}, 0\right)\right)=d(A, B) .
$$

Then, $\left(u_{1}, 0\right)$ and $\left(u_{2}, 0\right)$ become the members of $A_{0}$. Consequently, we have

$$
d\left(\left(u_{1}, 0\right),\left(u_{2}, 0\right)\right)=d\left(T\left(u_{1}, 0\right), T\left(u_{2}, 0\right)\right)=0 .
$$

By assuming that $\psi, \phi:[0, \infty) \rightarrow[0, \infty)$ such that $\psi(t)=2 t$ and $\phi(t)=t / 2$, we get

$$
\begin{aligned}
& \psi\left(d\left(\left(u_{1}, 0\right),\left(u_{2}, 0\right)\right)\right)=\psi\left(d\left(T\left(u_{1}, 0\right), T\left(u_{2}, 0\right)\right)\right)=0, \\
& \psi\left(m\left(\left(x_{1}, 0\right),\left(x_{2}, 0\right)\right)\right)-\phi\left(m\left(\left(x_{1}, 0\right),\left(x_{2}, 0\right)\right)\right) \\
& \quad=\frac{3}{2} m\left(\left(x_{1}, 0\right),\left(x_{2}, 0\right)\right), \\
& \psi\left(m\left(T\left(x_{1}, 0\right), T\left(x_{2}, 0\right)\right)\right)-\phi\left(m\left(T\left(x_{1}, 0\right), T\left(x_{2}, 0\right)\right)\right) \\
& \quad=\frac{3}{2} m\left(T\left(x_{1}, 0\right), T\left(x_{2}, 0\right)\right) .
\end{aligned}
$$

Therefore, $T$ is both generalized proximal weak contraction on $A$ and generalized proximal weak contraction on $B$. Hence $T$ is generalized proximal weak contraction such that $T\left(A_{0}\right) \subseteq B_{0}$. So, all the hypotheses of Theorem 9 are satisfied. Further, it is easy to see that $(-1,0)$ is the unique element satisfying the conclusion of Theorem 9 .

It is easy to see that a self-mapping that is a generalized proximal weak contraction reduces to a generalized $(\psi, \phi)$ weak contraction. Hence the above Theorem 9 gives rise to the following fixed point theorem, due to Dorić [9], which in turn extends the famous contraction principle.

Corollary 11. Let $(X, d)$ be a nonempty complete metric space and let $T: X \rightarrow X$ be a generalized proximal weak contraction map. Then $T$ has a unique fixed point. 
Theorem 12. Let $(A, B)$ be a pair of two nonempty closed subsets of a complete metric space $X$ such that $B$ is approximatively compact with respect to $A$ and $A_{0}$ is nonempty. Let $T: A \rightarrow B$ be a map satisfying the following conditions:

(i) $T$ is a generalized proximal weak contraction on $A$,

(ii) $T\left(A_{0}\right) \subseteq B_{0}$.

Then, there exists a unique $x \in A$ such that $d(x, T x)=d(A, B)$. Further, for any fixed element $x_{0} \in A_{0}$, the sequence $\left\{x_{n}\right\}$, defined by $d\left(x_{n+1}, T x_{n}\right)=d(A, B)$, converges to the element $x$.

Proof. Following the proof of Theorem 9, there exists a sequence $\left\{x_{n}\right\}$ in $A$ satisfying the following conditions:

$$
d\left(x_{n+1}, T x_{n}\right)=d(A, B), \quad \forall n \in \mathbb{N}
$$

and $x_{n}$ converges to $x$ in $A$. Let us now prove that $x$ is best proximity point for $T$.

Note that from (37), we have

$$
\begin{aligned}
d(x, B) & \leq d\left(x, T x_{n}\right) \leq d\left(x, x_{n+1}\right)+d\left(x_{n+1}, T x_{n}\right) \\
& \leq d\left(x, x_{n+1}\right)+d(A, B) \\
& \leq d\left(x, x_{n+1}\right)+d(x, B) .
\end{aligned}
$$

Since $x_{n} \rightarrow x$, we get $d\left(x, T x_{n}\right) \rightarrow d(x, B)$. Since $B$ is approximatively compact with respect to the set $A$, it follows that the sequence $\left\{T x_{n}\right\}$ has a subsequence converging to some $y$ in B. Now arguing like Step 3 and Step 4 of Theorem 9, we get the required result.

In what follows we prove that Theorem 12 is still valid for $B$ not necessarily approximatively compact with respect to $A$, assuming that $A_{0}$ is closed.

Theorem 13. Assume that " $A_{0}$ is closed" instead of "the statement $B$ is approximatively compact with respect to $A$ " in Theorem 12.

Proof. Following the proof of Theorem 9, there exists a sequence $\left\{x_{n}\right\}$ in $A$ satisfying the following condition:

$$
d\left(x_{n+1}, T x_{n}\right)=d(A, B),
$$

and $x_{n}$ converges to $x$ in $A$. Note that the sequence $\left\{x_{n}\right\}$ in $A_{0}$ and $A_{0}$ is closed. Therefore, $x \in A_{0}$. Since $T\left(A_{0}\right) \subseteq B_{0}$, we get $T x \in B_{0}$. Since $T x \in B_{0}$, there exists $z \in A$ such that $d(z, T x)=d(A, B)$. Since $T$ is a generalized proximal weak contraction on $A$, we have

$$
\psi\left(d\left(x_{n+1}, z\right)\right) \leq \psi\left(m\left(x, x_{n}\right)\right)-\phi\left(m\left(x, x_{n}\right)\right),
$$

where $m\left(x, x_{n}\right)=\max \left\{d\left(x_{n}, x\right), d\left(x_{n}, x_{n+1}\right), d(x, z),\left(d\left(x_{n}\right.\right.\right.$, $\left.\left.z)+d\left(x, x_{n+1}\right)\right) / 2\right\}$.

Now arguing like Step 3 and Step 4 of Theorem 9, we get the required result.

Theorem 14. Assume that " $T$ is continuous" instead of the statement " $B$ is approximatively compact with respect to $A$ " in the Theorem 12 .
Proof. Following the proof of Theorem 9, there exists a sequence $\left\{x_{n}\right\}$ in $A$ satisfying the following condition:

$$
d\left(x_{n+1}, T x_{n}\right)=d(A, B),
$$

and $x_{n}$ converges to $x$ in $A$. Since $T$ are continuous, we have

$$
d(x, T x)=\lim _{n \rightarrow \infty} d\left(x_{n+1}, T x_{n}\right)=d(A, B) .
$$

Uniqueness follows the same as in Theorem 9.

\section{Conflict of Interests}

The authors declare that there is no conflict of interests regarding the publication of this paper.

\section{Authors' Contribution}

All authors contributed equally and significantly in writing this paper. All authors read and approved the final paper.

\section{References}

[1] Ya. I. Alber and S. Guerre-Delabriere, "Principle of weakly contractive maps in Hilbert spaces," in New Results in Operator Theory and Its Applications, vol. 98, pp. 7-22, 1997.

[2] B. E. Rhoades, "Some theorems on weakly contractive maps," Nonlinear Analysis, Theory, Methods and Applications, vol. 47, no. 4, pp. 2683-2693, 2001.

[3] H. Aydi, M.-F. Bota, E. Karapınar, and S. Moradi, "A common fixed point for weak $\phi$-contractions on b-metric spaces," Fixed Point Theory, vol. 13, no. 2, pp. 337-346, 2012.

[4] M. Jleli, E. Karapınar, and B. Samet, "Fixed point results for almost generalized cyclic $(\psi, \phi)$-weak contractive type mappings with applications," Abstract and Applied Analysis, vol. 2012, Article ID 917831, 17 pages, 2012.

[5] E. Karapınar and I. S. Yuce, "Fixed point theory for cyclic generalized weak $\varphi$-contraction on partial metric spaces," Abstract and Applied Analysis, vol. 2012, Article ID 491542, 12 pages, 2012.

[6] E. Karapınar, "Best proximity points of Kannan type cyclic weak $\varphi$-contractions in ordered metric spaces," Analele Stiintifice ale Universitatii Ovidius Constanta, vol. 20, no. 3, pp. 51-64, 2012.

[7] E. Karapınar, "Fixed point theory for cyclic weak $\phi$-contraction," Applied Mathematics Letters, vol. 24, no. 6, pp. 822-825, 2011.

[8] P. N. Dutta and B. S. Choudhury, "A generalisation of contraction principle in metric spaces," Fixed Point Theory and Applications, vol. 2008, Article ID 406368, 8 pages, 2008.

[9] D. Dorić, "Common fixed point for generalized $(\psi, \varphi)$-weak contractions," Applied Mathematics Letters, vol. 22, no. 12, pp. 1896-1900, 2009.

[10] A. A. Eldred and P. Veeramani, "Existence and convergence of best proximity points," Journal of Mathematical Analysis and Applications, vol. 323, no. 2, pp. 1001-1006, 2006.

[11] M. A. Al-Thagafi and N. Shahzad, "Convergence and existence results for best proximity points," Nonlinear Analysis. Theory, Methods \& Applications, vol. 70, no. 10, pp. 3665-3671, 2009.

[12] S. Sadiq Basha and P. Veeramani, "Best proximity pairs and best approximations," Acta Scientiarum Mathematicarum, vol. 63, no. 1-2, pp. 289-300, 1997. 
[13] W. A. Kirk, S. Reich, and P. Veeramani, "Proximinal retracts and best proximity pair theorems," Numerical Functional Analysis and Optimization, vol. 24, no. 7-8, pp. 851-862, 2003.

[14] S. Sadiq Basha and P. Veeramani, "Best proximity pair theorems for multifunctions with open fibres," Journal of Approximation Theory, vol. 103, no. 1, pp. 119-129, 2000.

[15] V. Sankar Raj and P. Veeramani, "Best proximity pair theorems for relatively nonexpansive mappings," Applied General Topology, vol. 10, no. 1, pp. 21-28, 2009.

[16] S. Sadiq Basha, "Best proximity points: optimal solutions," Journal of Optimization Theory and Applications, vol. 151, no. 1, pp. 210-216, 2011.

[17] S. Sadiq Basha, "Best proximity point theorems: an exploration of a common solution to approximation and optimization problems," Applied Mathematics and Computation, vol. 218, no. 19, pp. 9773-9780, 2012.

[18] V. Pragadeeswarar and M. Marudai, "Best proximity points: approximation and optimization in partially ordered metric spaces," Optimization Letters, vol. 7, no. 8, pp. 1883-1892, 2013. 


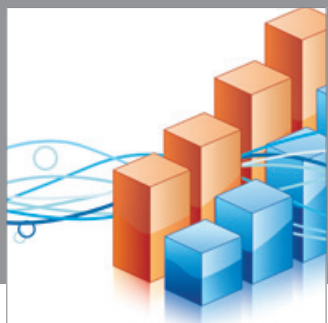

Advances in

Operations Research

mansans

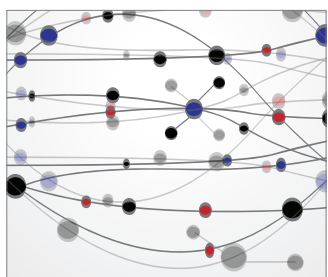

The Scientific World Journal
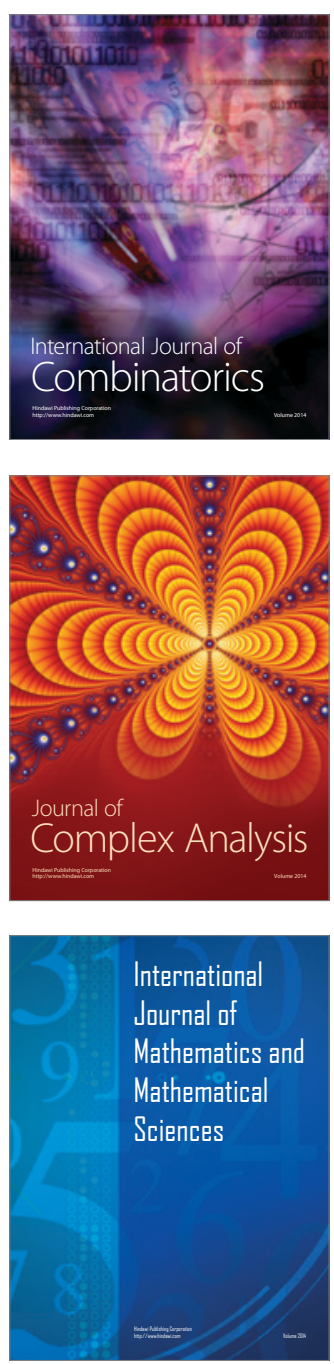
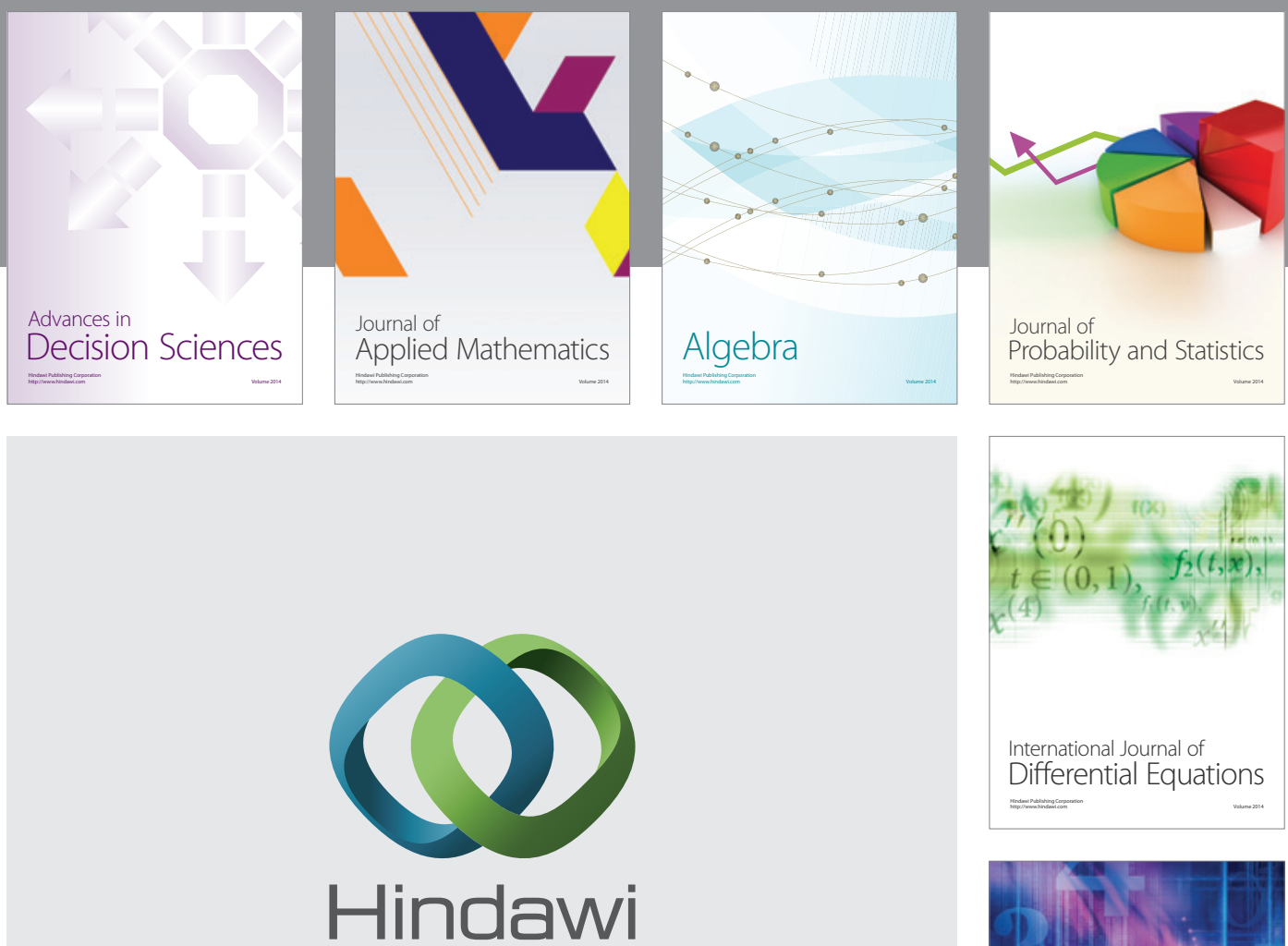

Submit your manuscripts at http://www.hindawi.com
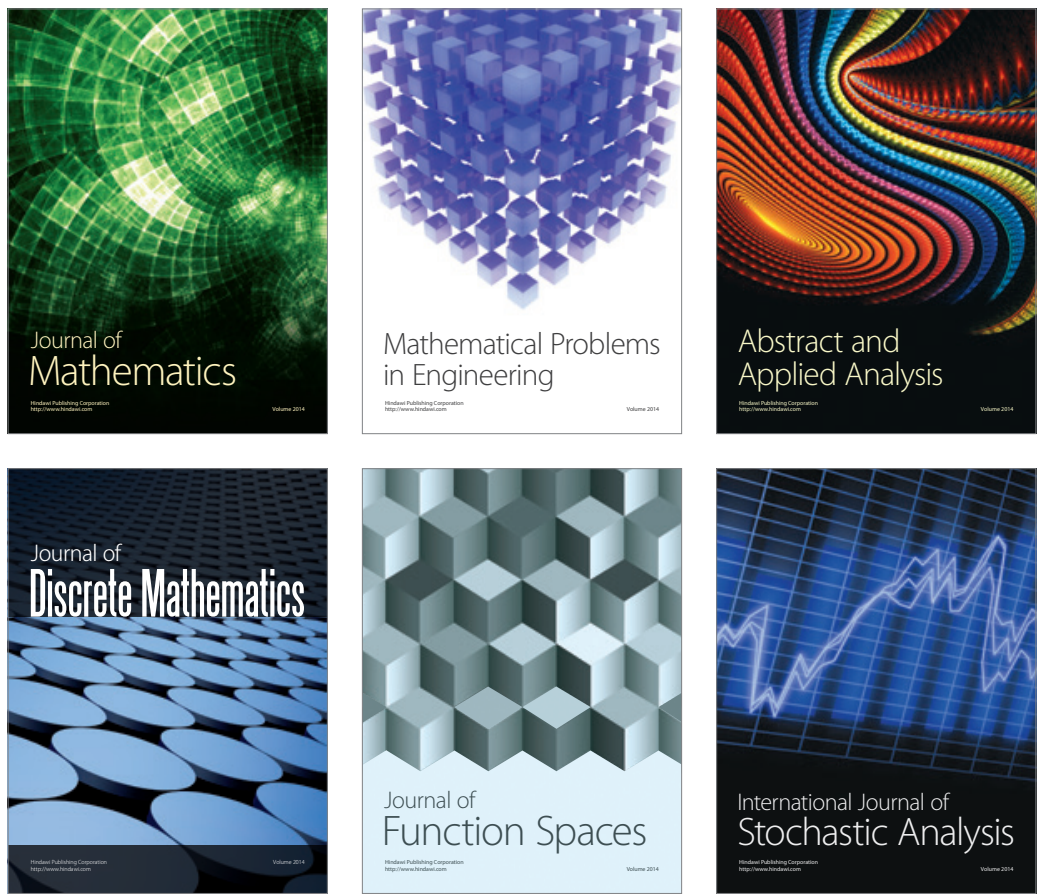

Journal of

Function Spaces

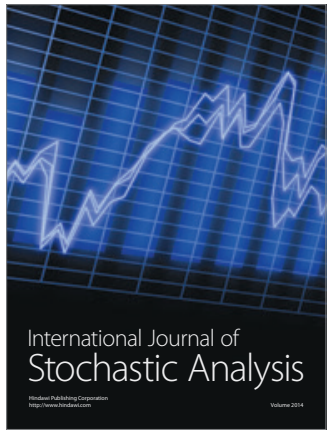

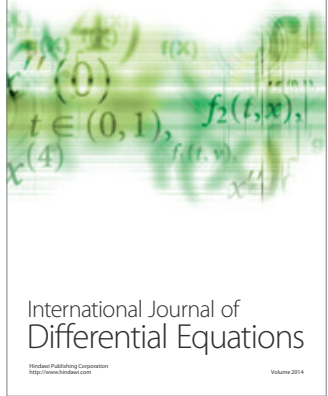
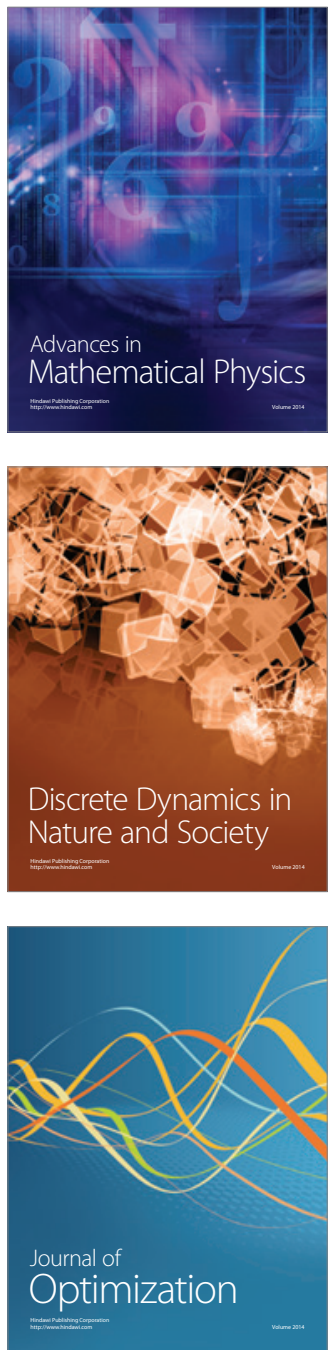